\title{
Equatorial
}

\section{A festa das primícias na comunidade amazônica de Vila Verde/Pará}

\author{
Wanessa Pires Lott \\ Professora Adjunta \\ Universidade Federal do Pará
}

Solange da Cruz Pereira Oliveira

Universidade Federal do Pará

\section{RESUMO}

O presente trabalho ressalta a importância da Festa das Primícias (ou a festa de Shavnot ou Pentecostes) na comunidade de Vila Verde localizada no estado do Pará. A festa ultrapassa o significado religioso pertinente aos membros da Assembleia de Deus e se coloca como um importante evento cultural para comunidade local. Optou-se por perceber a festa pelo recurso metodológico da observação participante, mas sem ter o intuito de fazer uma etnografia. Assim, a fala de membros da comunidade local e a observação da festa no ano de 2019 foram as fontes principais deste estudo, somado ao estudo bibliográfico sobre o tema.

Palavras-chave: Festa das Primícias; Assembleia de Deus; cultura local; Antropologia da festa. 


\title{
The "Primícias" feast in the Amazon community of Vila Verde/Pará
}

\begin{abstract}
The present work emphasizes the importance of the "Primícias" festival (orthe festival of Shavuot or Pentecost) in the community of Vila Verde located in the state of Pará. The festival goes beyond the religious meaning pertinent to the members of the Assembly of God and is an important cultural event for the local community. We chose to perceive the festival through the methodological resource of participant observation, but without the intention of making an ethnography. Thus, the speech of members of the local community and the observation of the festival in 2019 were the main sources of this study, as well as the bibliographic study on the theme.
\end{abstract}

Keywords: Primicias feast; Assembly of God; local culture; Anthropology of festivals.

\section{La fiesta de las Primícias en la comunidad amazónica de Vila Verde/Pará}

\section{RESUMEN}

El presente trabajo enfatiza la importancia del la fiesta de las Primícias (o la fiesta de Shavuot o Pentecostés) en la comunidad de Vila Verde ubicada en el Estado de Pará. La fiesta va más allá del significado religioso pertinente para los miembros de la Asamblea de Dios y es un evento cultural importante para la comunidad local. Elegimos percibir el evento por el recurso metodológico de observación participante, pero sin la intención de hacer una etnografía. Por lo tanto, el discurso de los miembros de la comunidad local y la observación de la fiesta en 2019 fueron las principales fuentes de este estudio, junto con el estudio bibliográfico sobre el tema.

Palabras clave: fiesta de las Primícias; Asamblea de Dios; cultura local; Antropología de la fiesta. 


\section{Introdução}

A Vila Verde é uma comunidade do estado do Pará na região Norte do Brasil. Está localizada às margens da BR 308, que liga os municípios de Bragança-Viseu, entre a Vila da Travessa do Dez e Emboraí Grande (fig. 1). Pertence ao município de Augusto Corrêa, que tem cerca de 40 mil habitantes distribuídos em quatro distritos: a sede, Aturiaí, Emboraí e Itapixuna, além das demais vilas (IBGE, 2020a). A maioria das pessoas mora na zona rural e seguem a religião católica, no entanto, em Vila Verde, a Igreja Assembleia de Deus detém o maior número de fiéis ${ }^{1}$.

Dentre as celebrações proferidas pela Assembleia de Deus, destaca-se, neste estudo, a festa de origem rabínica denominada como Festa de Shavnot ou Pentecostes ou das Primícias ${ }^{2}$, sendo esta última designação a utilizada na comunidade. Cabe ressaltar que a palavra Shavnot significa em hebraico "semanas", pois a festa é historicamente celebrada sete semanas após a Páscoa, mas no decorrer dos tempos, as igrejas deslocaram suas celebrações de acordo com a necessidade local. A festa, que tem bases em livros bíblicos ${ }^{3}$, é realizada para agradecer a Deus pela safra oriunda do plantio. Com ocorrência anual em Vila Verde desde 2001, a celebração inicialmente era feita no mês de setembro, no entanto, com a mudança da colheita local, passou a ser realizada no penúltimo final de semana do mês de outubro.

Assim sendo, este artigo tem como objetivo apresentar a referida festa, tendo como base principal o trabalho de campo feito no ano de 2019. No decorrer da apresentação da celebração, os conceitos antropológicos que tangem os temas de festa e de religião servirão como suporte teórico para a percepção do objeto de estudo. O texto é dividido em quatro partes, para além desta introdução. Na primeira a Assembleia de Deus será brevemente apresentada e, em seguida, a igreja da localidade. No terceiro momento, a festa será o foco principal e, por fim, haverá uma consideração final sobre o tema.

\section{O pentecostalismo e a formação da Assembleia de Deus}

No senso comum brasileiro, são denominados os cristãos não pertencentes à Igreja Católica como "crentes" ou "evangélicos", no entanto há diferenças significativas nesta convenção cotidiana (MAFRA, 2001). Os pentecostais fazem parte do movimento que surgiu do processo histórico iniciado ainda na Reforma Protestante do século XVI e o termo é utilizado para designar aqueles "que acreditam e aceitam a promessa do 
derramamento do Espírito Santo" (MACHADO, 1997, p. 38). Este derramamento, ou "primeiras chuvas", está descrito no Novo Testamento e no pentecostalismo moderno estas bênçãos são designadas como as "últimas chuvas" do Espírito Santo, que por sua vez, restauram os dons divinos com intuito de esperar o retorno do dito Salvador (MATOS, 2006). No Brasil, o surgimento do pentecostalismo iniciou no século XX, em contraposição à hegemonia e ao fortalecimento da Igreja Católica ${ }^{4}$ e pode ser apresentado em três grandes ondas. A primeira designada como "clássica", com a criação da Congregação Cristã do Brasil em São Paulo (1910) e da Assembleia de Deus em Belém (1911).

Os primeiros lugares no Pará que receberam a mensagem pentecostal foram: Soure e Mosqueiro, na Ilha de Marajó (Daniel Berg, 1911); Bragança (Daniel Berg, 1912); Xarapucu e Catipuru (Daniel Berg, 1913); Estrada de Ferro Belém-Bragança, Igarapé-Assu, Benevides, Capanema, Timboteua, Peixe-Boi e Bragança (Clímaco Bueno Aza, 1913); Ilha Caviana (Daniel Berg, 1914); Afuá, Ilha de Marajó (Gunnar Vingren e Daniel Berg, 1914); São Luís do Pará (1915); Assaisal (Bonito) (Joaquim Amaro do Nascimento, Francisco Santos Carneiro e João Paraense, 1919); e vários outros lugares foram sendo visitados pelos primeiros missionários e crentes da $\mathrm{AD}$ de Belém. (ADNB, 2019, s/p).

A segunda onda ocorreu nas décadas de 1950 e 1960 com a Igreja do Evangelho Quadrangular (1951), a Igreja Brasil para Cristo (1955) e a Igreja Deus é Amor (1962). A última onda aconteceu com a Igreja Universal do Reino de Deus (1977) e a Igreja Internacional da Graça de Deus (1980) (FRESTON, 1994) ${ }^{5}$. Na primeira onda, principalmente a partir da década de 1930, a colaboração das Assembleias de Deus dos Estados Unidos se deu de forma significativa por meio dos missionários enviados ao país. Estes se envolveram de forma mais direta com a estrutura teológica da doutrina e o movimento cresceu principalmente entre as pessoas de origem humilde e desfavorecida no Brasil.

Os primeiros pentecostais no Brasil historicamente ministram entre as classes mais carentes. Suas igrejas foram plantadas em comunidades pobres, nas periferias e nos vilarejos, pelo Brasil todo. Durante os primeiros 40 e 50 anos após o início do Movimento Pentecostal no país, as classes média e alta deixaram de ser alcançadas pelo pentecostalismo (MOURA, 2010, p. 87). 
Posteriormente, a Assembleia de Deus voltou para as classes sociais mais altas, se estabelecendo principalmente nas regiões metropolitanas e nos grandes centros. Com a expansão da igreja, ocorreram algumas fragmentações internas levando a uma nova disposição voltada para uma administração mais autônoma. Ou seja, as Assembleias de Deus brasileiras se organizam em um episcopado não territorial, pois cada ministério é constituído por sua igreja sede com suas respectivas filiadas. Os sistemas de administração são um misto entre o sistema episcopado e o sistema congregacional, onde os assuntos são primeiro tratados pelo ministério - com forte influência da liderança pastoral - e em seguida são levados às assembleias para serem apenas referendados. Desta maneira, os pastores das Assembleias de Deus podem estar ligados ou não às convenções estaduais.

Neste contexto, as igrejas possuem maior liberdade de se adaptarem às realidades locais e, atualmente, têm-se mostrado mais flexíveis em termos de diálogo com outras igrejas cristãs. Esta atitude é pertinente na comunidade de Vila Verde, principalmente nos dias de celebrações religiosas locais. Católicos participam das festas da Assembleia de Deus - principalmente da Festa das Primícias - e assembleianos participam das celebrações católicas.

\section{A Assembleia de Deus de Vila Verde}

"A Assembleia de Deus é sem dúvida a denominação mais presente na região Norte do Brasil" (PANTOJA, 2011, p. 67) e, como dito, cada uma das igrejas tem suas especificidades, que por sua vez são pertinentes à realidade local. Assim sendo, apesar de alguns exemplos de outras comunidades no decorrer do texto, é importante ressaltar que este estudo tem como fonte principal a percepção da Assembleia de Deus da Vila Verde e neste ponto do texto iremos apresentar a visão desta igreja, tendo como base principal a fala do pastor responsável, que se mostra extremamente orgulhoso de fazer parte da comunidade assembleiana. Tal postura é também verificada em outros locais do Pará. Na região do Marajó, ser membro da igreja traz "um status diferenciado, sobretudo para as famílias mais humildes” (PANTOJA, 2011, p. 67), e este lugar social é marcado no cotidiano principalmente pelas roupas utilizadas.

No pensamento dominante local as vestes de uma pessoa estão diretamente relacionadas ao seu prestígio e, em alguns casos, ao seu caráter, sobretudo no caso de mulheres. Assim, é muito comum que as pessoas façam questão de 
manter muito rigor e zelo por sua aparência, é necessário não apenas ser evangélico, mas, sobretudo parecer um evangélico. (PANTOJA, 2011, p. 67).

Esta necessidade de afirmação de pertencimento à Assembleia de Deus também comum em Vila Verde. A conversão geralmente acontece não só pela questão supracitada do status, como também pelo acreditar que, ao se converterem ao pentecostalismo e, por conseguinte, ao alterar seu modo de viver, acarretará na solução dos problemas diários além da salvação após a morte (BOYER, 1996; NOVAES, 1985). Desta maneira, a conversão pode ser entendida como uma ruptura da vida antiga a favor de uma nova vida motivada pelos desígnios divinos (ROBBINS, 2011) ${ }^{6}$, fato este que ocorreu com o atual sacerdote da Assembleia de Deus da Vila Verde, o pastor Antônio Lisboa Batista.

Nascido no ano de 1958, na cidade de Itaituba/Pará, o pastor iniciou seus estudos nesta cidade, mas concluiu o ensino médio na capital do Estado, Belém. Em 1979 estudou por quatro anos teologia e na sequência pastoreou por sete anos em uma igreja. Sua conversão na Assembleia de Deus ocorreu da seguinte forma:

Desde o ano de 1980... 1980, a minha conversão foi algo assim impressionante, eu era um jovem que tinha uma boa rentabilidade, trabalhava, ganhava bastante dinheiro, eu tinha aquele lado social, gostava de estar junto daquela juventude, não era aquele jovem que gostava de estar no canto das esquinas, mas tinha aquele momento específico com os meus colegas. Um dia nós estávamos em um bar brincando uma sinuca e eu tive um desentendimento com um dos meus colegas, eu saí um pouco contrariado daquele bar e passando em frente a uma Igreja Evangélica Assembleia de Deus na cidade de Itaituba, eu ouvia como se uma voz dissesse pra mim "entra", eu tentei resistir, mas a voz ela falou mais forte comigo dizendo "entra", eu entrei naquele templo da Assembleia de Deus, ouvi um pastor por nome Alexandre Pinheiro de Brito que pregava a palavra de Deus, e no momento que ele fez o convite, veio um moço até mim e disse assim: "Você quer aceitar Jesus meu jovem", eu disse "não, eu não quero aceitar Jesus". Quando aquele moço saiu, eu ouvi uma outra vez a voz dizer, "covarde, vai", e eu me levantei e fui até o altar aonde estava lotado o templo, dobrei meus joelhos e o pastor perguntou, "você quer aceitar Jesus?". E eu disse: "eu quero". Aceitei Jesus, e eu lembro que uma jovem naquele dia, ela olhou pra mim e disse assim: "você não vai permanecer". Eu disse, "por que?". Disse ela, "porque você tem um tipo de vida diferente, você é um jovem que tem dinheiro, e que vive uma vida assim, junto com os outros jovens, que eu acho que você não vai permanecer". No entanto, isso tudo aconteceu, e desde esse ano pra cá, eu venho conduzindo a minha vida cristã diante de Deus, e Deus tem me dado graça e vitória. (BATISTA, entrevista, 09/09/2019, Vila Verde 2019). 
O pastor conheceu a comunidade da Vila Verde em 2005, quando era o vicepresidente da Assembleia de Deus da cidade Bragança/Pará. Sua ida para a cidade foi em função de representar o presidente da Assembleia de Deus na Festa das Primícias. Anos mais tarde, em 2013 ele foi deslocado para ser o pastor da igreja de Vila Verde.

A Vila Verde tem um povo bem pacato, mas é um povo que nós não poderíamos nem dizer que eles têm um lazer, porque o lazer da população de Vila Verde é algumas vezes que eles saem para os igarapés, a praia daqui da Vila Verde fica a quase cem quilômetros, que seria a praia de Ajuruteua. E é um povo que trabalha noite e dia, nós poderíamos ter um exemplo muito positivo desta população daqui de Vila Verde, porque a atividade deles é incansável. Eu sempre digo que eu nunca vi por onde já passei, já estive na região do Sul do Pará, Baixo Amazonas, mas eu nunca vi um povo pra trabalhar tão sério como este povo daqui de Vila Verde. (BATISTA, entrevista, 09/09/2019, Vila Verde 2019).

Como destacado anteriormente sobre a flexibilidade da Assembleia de Deus a partir da terceira onda do pentecostalismo brasileiro, a igreja de Vila Verde tem forte afinidade entre a Igreja Católica local, principalmente nos momentos de festividade.

Inclusive em nossas principais festas que nos colocaríamos aqui como o Congresso Unificado, que é onde nós unificamos crianças, jovens, adolescentes, senhores e senhoras, é [quando] acontece este evento que se transforma numa cultura do povo. Segundo evento que acontece muito importante é no mês de julho quando chega a época das férias, nós temos um evento aqui intitulado Escola Bíblica de Férias, aonde nós unificamos todas as crianças daqui da Vila Verde, esta redondeza aqui. Trabalham tanto as senhoras evangélicas quanto as senhoras católicas, trabalham pra fazer acontecer esse trabalho com as nossas crianças. São três dias que eles recebem ensinamentos, brincadeiras, eles recebem oficinas de fazer algumas atividades, então todo este trabalho é feito, e eu percebo que quarenta por cento das crianças que participam conosco elas fazem parte da Igreja Católica, são filhos de pessoas católicas e tem uma fé católica, então, isso é muito importante. A terceira festa que acontece aqui na nossa região, é o maior evento, não só falando de Vila Verde, mas falando de Região Bragantina, é uma das maiores festividades que acontece, é a Festa das Primícias. (BATISTA, entrevista, 09/09/2019, Vila Verde 2019).

Neste ponto da fala do pastor, ele destaca a Festa das Primícias, que será explicada posteriormente neste artigo. No entanto, é importante trazer a fala de outro importante membro da comunidade local, que nos mostra esta relação próxima entre as duas igrejas da vila: a Assembleia de Deus e a Igreja Católica. A entrevista foi feita com uma professora aposentada da rede estadual de 50 anos de idade, Silveira. Ela é católica e foi 
catequizada por sua mãe e em seguida por sua madrinha. Hoje ela vive "apenas de contribuir com a comunidade na parte religiosa e com os agricultores lutando com o sindicato dos trabalhadores rurais" (SILVEIRA, entrevista, 15/09/2019, Vila Verde). Ela descreve a Vila Verde e também destaca as festividades locais.

A Vila Verde também é uma comunidade agrícola onde a comunidade vive da agricultura e tem seus lazeres como futebol, festas tradicionais que eles ainda usam. E tem a festividade, que o padroeiro de lá é São José, né, e a festividade de lá acontece no mês de março, e aqui - como nós somos vizinhos, né, Emboraí Grande e Vila Verde -, também no Emboraí Grande a festividade é no mês de dezembro, que é a festa de Nossa Senhora da Conceição. E a gente se relaciona muito bem com as outras denominações religiosas, como acontece na Vila Verde a grande Festa das Primícias, muitas pessoas da Igreja Católica contribuem com os seus, com os seus dízimos né, levam seus dízimos de produção pra lá pra igreja e muitos participam. (SILVEIRA, entrevista, 15/09/2019, Vila Verde).

A entrevistada afirma que, além da Festa das Primícias, na comunidade há outras festividades que se destacam nesse contexto cultural de festividades religiosas. No entanto, a que mais se destaca é a Festa das Primícias. Apesar de a entrevistada não ser uma participante frequente, ela também tem a sua percepção da festa.

Tenho conhecimento, sei como é que acontece, é uma festa grandiosa que acomoda uma grande multidão de pessoas que vêm de toda região e trazem missionários de outros estados, de São Paulo, de outros estados, vêm missionários que fazem acontecer essa grande festa da Primícia aqui na Vila Verde e que hoje já se expande, né, por várias outras localidades vizinhas daqui também. (SILVEIRA, entrevista, 15/09/2019, Vila Verde).

Esta convivência, apresentada como pacífica pelos membros da comunidade, talvez encontra justificativa na pouca presença dos católicos devido de um padre no cotidiano dos habitantes, tornando sua voz diminuta em relação aos assembleianos. Apesar de haver uma pequena igreja católica em Vila Verde, esta oferece missas e/ou outras atividades de forma esporádica.

\section{A festa das Primícias}

Como dito, a festa das Primícias é realizada na Vila Verde que fica a cerca de 300 km da capital do Estado do Pará, Belém. 

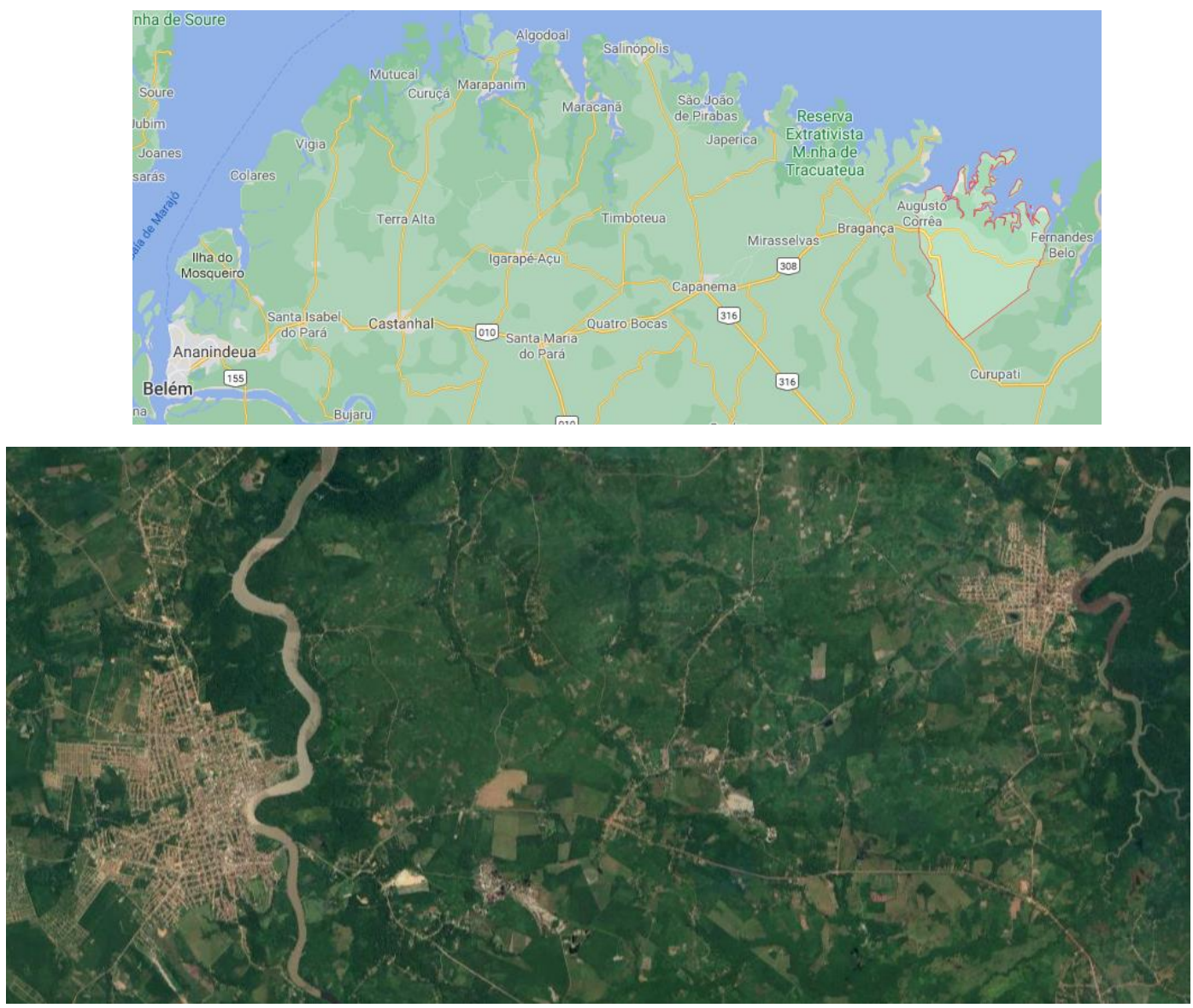

Figura 1 - Mapa de Localização de Vila Verde. Fonte: Google maps, 2019.

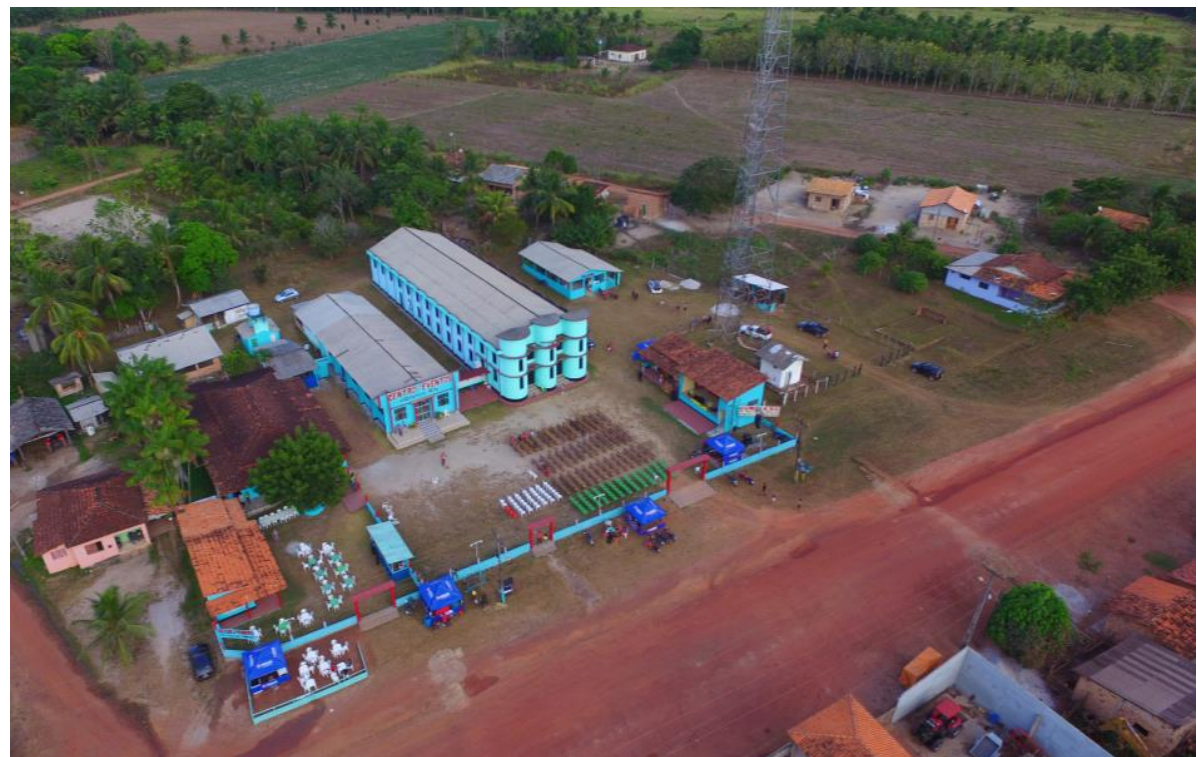

Figura 2: Vista aérea de Vila Verde com destaque para a Assembleia de Deus. Fonte: Acervo das autoras, 2019

Além da relevância para a comunidade local, a festa é um objeto privilegiado de estudo, principalmente no âmbito da Antropologia. Esta coloca a festa como destaque 
nos estudos da religião, uma vez que as festas religiosas pertencem ao espaço/tempo do sagrado, onde há um corte com o cotidiano, com suas limitações ordinárias, possibilitando um retorno ao espaço/tempo da origem, da criação, do caos inicial. $\mathrm{Na}$ festa, o indivíduo e o grupo rompem com as pequenas preocupações cotidianas, vivenciando um tempo de intensas emoções, retornando aos primeiros tempos da criação para que haja uma revigoração do ser, um reencontro com a plenitude da vida para enfrentar o ciclo rotineiro (DURKHEIM, 2003). A festa institui uma abertura para o Grande Tempo, o momento em que os homens abandonam o devir para alcançar o reservatório das forças todo-poderosas que o paraíso primordial aciona (CALLOIS, 1988), e estes movimentos são identificados na Festa das Primícias de Vila Verde.

A festa das Primícias é também conhecida como a festa de Shavnot ou a festa de Pentecostes, e trata-se da segunda das três grandes festas de Israel, no entanto, esta festa passou no decorrer dos tempos "a celebrar a memória da Aliança do Sinai, com o 'dom' da Torá, sem nunca perder o seu caráter agrícola, chegando ao universo cristão celebrando (...) os 'dons' do Espírito Santo”. Esta modificação ao longo da história, permitiu que "o caráter agrícola se sobressai ao contexto histórico, sendo este assumido a partir da influência cristã, ao transpor a solenidade judaica para o universo cristão vinculando e concluindo o período pascal" (ARAÚJO, 2015, p. 01). A referência agrícola se mostra como um foco importante para a comunidade de Vila Verde, não só pela agricultura ser a maior fonte da economia local, mas, sobretudo, pelo forte simbolismo que é epifanizado na festa das Primícias. Parte da colheita é efetivamente e simbolicamente entregue à Assembleia de Deus em retribuição às orações proferidas pelo pastor na época do plantio. Assim sendo, a natureza dos alimentos produzidos pela comunidade não pode ser tida apenas no sentido material, mas também em sua dimensão simbólica, como destacado nos estudos sobre a dádiva (MAUSS, 2003).

Ademais, por se tratar de um ritual cíclico e agrícola a festa das Primícias pode ser analisada também na ótica do sacrifício. Os sacrifícios aos deuses demonstram as relações de trocas entre os seres profanos e os seres sagrados por meio da vítima, que intermedia os dois mundos. Nesta festa, a vítima sacrificada é o alimento, que ao ser doado aos deuses evidencia o fenômeno religioso. Desta maneira, por intermédio do sacrifício e do altruísmo do indivíduo, as forças coletivas são reiteradas (MAUSS e HUBERT, 2017).

A primeira festa das Primícias na localidade data de setembro de 2001 e sua justificativa se aproxima da ideia de que os rituais devem ser realizados nos momentos 
de crise para que haja o reestabelecimento do equilíbrio na comunidade (TURNER, 1974). O pastor Isaias Rodrigues Ribeiro ${ }^{7}$ observou o dia a dia dos trabalhadores da comunidade e identificou que no período de plantação todos ficavam muito ansiosos. Assim, os fiéis pediam constantemente orações em prol de uma boa safra e ao final da colheita os fiéis entregavam parte dos alimentos para a igreja em agradecimento a Deus pelas suas safras.

Fiquei imaginando o que fazer pra que essa comunidade tivesse um momento de regozijo e pudesse agradecer a Deus de outra maneira em forma de jubilo, e que essas ofertas fossem revestidas para a igreja em forma de construção porque na época estávamos precisando de um templo para maior comodidade dos fiéis. Foi então que estávamos estudando uma revista da Escola Bíblica Dominical que comentava sobre as Festas que Deus instruiu ao seu povo pra fazerem no início e final de suas colheitas, então fui buscar bases bíblicas e me deparei com muitos textos que falavam das festas, inclusive Festa das Primícias, desde então muito nos empenhamos para realizá-la e conseguimos com muito esforço. (RIBEIRO, entrevista, 05/08/2019, Vila Verde).

Segundo os assembleianos, essa alegria contagia até mesmo quem não é da Assembleia de Deus. Na fala da entrevistada católica, ela conta que vê a comunidade de maneira geral envolvida com a festa, onde nesse momento de festividade não há, aparentemente, nenhuma desavença religiosa.

A boa vontade do povo. Todos se dedicam é, se oferecem mesmo pra trabalhar, porque é um trabalho muito grande e quantos católicos vão e se interessam entram lá mesmo no trabalho, ficam lá todos os dias ajudando na alimentação, fazendo a confecção do alimento, na limpeza, na organização lá e participam muito bem. Acho isso muito bonito, porque quando nós também precisamos de ajuda dos nossos irmãos evangélicos eles também são solidários conosco, a gente tá numa luta, numa batalha, numa busca de uma, de um céu que nós buscamos pra nós. $\mathrm{E}$ a gente quer ir assim, todos juntos de mãos dadas, né, pra chegarmos ao nosso objetivo que é a nossa salvação de viver com o nosso Senhor no céu, todos juntos. (SILVEIRA, 2019: informação oral).

Assim, percebe-se nas falas dos membros da comunidade que a festividade traz momentos de alegria e comunhão. Durante o trabalho de campo realizado, não foi identificado nenhum dizer negativo e/ou postura contrária sobre a festa. Por ser uma comunidade pequena e com pouquíssimas atividades que propiciam o encontro, a festa anual é o grande momento de interligação ente os pares (fig. 2). Ademais, a figura do 
pastor é tida como uma autoridade respeitável, e sua fala é, possivelmente, a grande referência para os demais.

A festa das Primícias começou no dia 17 de setembro do ano de 2001, pelo pastor então, naquela época presidente da igreja aqui, que era o pastor Isaias Ribeiro. Ele foi o mentor e o executor da primeira Festa de Primícias, logo depois veio o pastor Nadilson. Pastor Isaias realizou cinco dessas festas, veio o pastor Nadilson e realizou mais sete dessas festas, sete e cinco: doze, doze festas foram realizadas e já em 2013, que foi a décima terceira, foi aonde eu assumi, e nós estamos realizando agora neste ano de 2019 a décima nona festa das Primícias. É aonde a gente percebe a união, a unidade do povo, toda a população da região. Eu sempre costumo dizer que a festa das Primícias ela não é realizada pela Assembleia de Deus unicamente Assembleia, ela é realizada pela população de Vila Verde, todos os moradores católicos aqui desta região eles se unificam a festa das Primícias que se transformou numa cultura pra o povo, e acontece que se não existir festa de Primícias, o povo... eles exigem, eles cobram. Uma coisa que eu acho interessante, é que algumas pessoas, mesmo sendo elas católicas ou evangélicas, elas se prontificam para contribuir para fazer suas doações, para dar seus donativos, suas criações, tudo quanto é enviado aqui para a festa das Primícias e colocada no nosso celeiro e que depois é vendido para as pessoas que vêm comprar. Logo depois estes valores são repassado para atividades da própria igreja investindo na própria igreja. Então isso é muito importante este elo, esta comunhão que existe entre a Assembleia de Deus, igreja católica que são as únicas duas religiões que têm aqui nesta região de Vila Verde, nós não temos uma outra igreja aqui, não tem Batista, não tem Adventista... é só Assembleia de Deus e Igreja Católica, o nosso elo é muito bom. (BATISTA, entrevista, 09/09/2019, Vila Verde 2019).

Não obstante a pronunciada felicidade da comunidade, tal sentimento pode ser analisado - para além da superficial percepção de fé e devoção pentecostal - sobre duas categorias antropológicas: a dádiva e a festa. Ao identificar a dádiva como "um crescimento da consciência de ser, a um incremento de autoridade e de fama para o doador", já que, "dar não é mais oferecer algo de si, mas adquirir esse si", ao doar alimentos para a Assembleia de Deus há, reciprocamente, o desenvolvimento do prestígio do indivíduo na comunidade, e por conseguinte uma felicidade resultante do reconhecimento individual pela sociedade (MAUSS, 2003, p. 258).

Ademais, o processo de dar, receber e retribuir se faz durante um ritual festivo, e como "toda festa $[\ldots]$ tem por efeito aproximar os indivíduos, pôr em movimento as massas e suscitar, assim, um estado de efervescência, às vezes delírio", muitas vezes tais ações são confundidas ou melhor dizendo, misturadas com o sentimento de felicidade (DURKHEIM, 2003, p. 417). Este grande envolvimento dos moradores da Vila Verde 
provoca uma ampliação da festa para além dos limites da religião pentecostal, sendo a festa tomada como um elemento da cultura local, que funciona como um período momentâneo de integração da sociedade (LOTT, 2009).

\begin{abstract}
Nos arrebata a alma de tanta alegria, porque podemos ver o agir de Deus de maneira sobrenatural. Quando iniciamos a coleta na sexta-feira às 7 horas da manhã vemos o celeiro, o curral, o galinheiro vazios e logo saem os caminhões, os carros, os tratores, as motos para pegarem as primícias dos nossos primicistas que estão longe e não tem como trazerem e nós mandamos pegar. E às 11 horas começam a chegar todos cheios dos animais como o boi, o cavalo, o porco, a galinha, o pato, o peru e as frutas de todas as espécies. Isso nos arrebata a alma, porque vemos que é uma questão de fé e Deus agindo e abençoando todos aqueles que creem. Com a saída desses caminhões para pegar as primícias nas localidades, nosso coração se enche de esperança em saber que voltarão cheios. A satisfação de chegar ao final da tarde e ver nossos espaços cheios nos alegra que não temos palavras expressar de tanta alegria, não tem explicação, é fé mesmo. (RIBEIRO, entrevista, 05/08/2019, Vila Verde).
\end{abstract}

Nas imagens abaixo, percebemos a movimentação da comunidade em torno dos preparativos da festa.

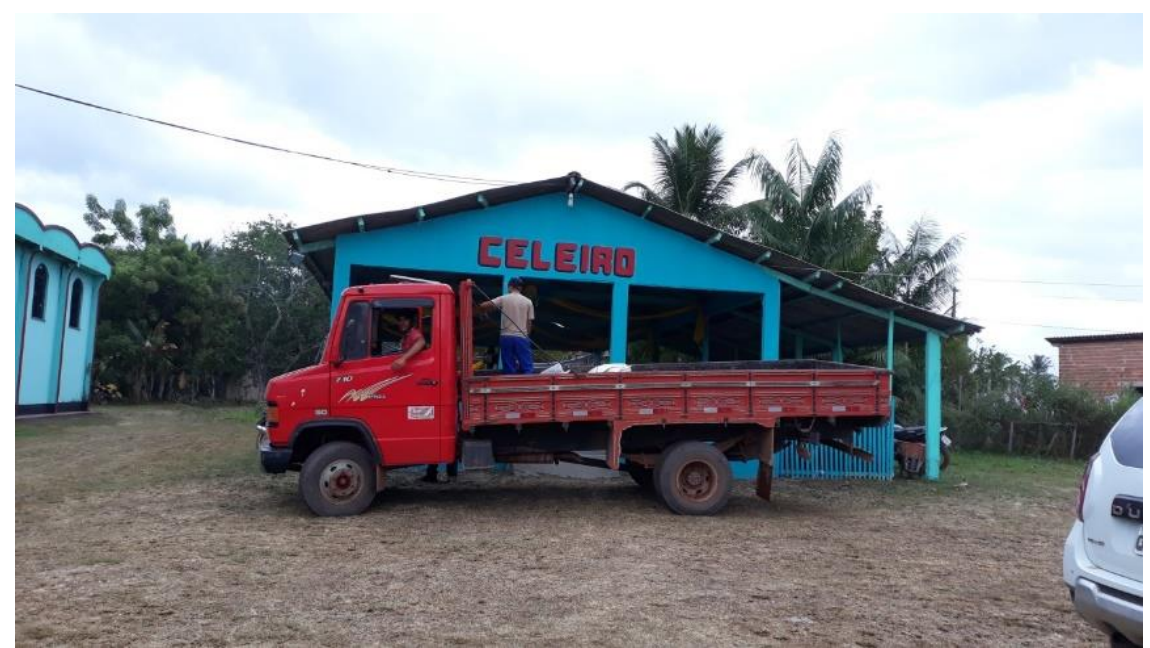

Figura 3: O celeiro onde guardam as primícias para a festa. Fonte: Acervo das autoras, 2019

A celebração ritual tem várias atrações, como a doação de alimentos, cerimônia de abertura, consagração das primícias, venda das primícias $^{8}$ e pregação da palavra de Deus, com convidados e cantores de outras localidades. Na primeira noite de festividade, sempre uma sexta-feira, há uma solenidade de abertura com louvores e cânticos pentecostais. Neste dia, os devotos são caracterizados com roupas que expressam as 
vestimentas do povo israelita, confeccionadas com base nas roupas judaicas de tradição rabínica (fig. 4). Todos trazem um cesto com seus frutos na hora da celebração representando as pessoas que doaram no decorrer do dia os alimentos.

Ressalta-se que a organização para a festa remente às simbologias e às representações características de um ritual, que são associadas à cosmogonia da Assembleia de Deus e dos aspectos ligados ao cotidiano agrário de Vila Verde. Assim sendo, tais representações simbólicas epifanizadas por meio das primícias e das vestimentas, estabelecem uma atmosfera ritual diferente da vida cotidiana da comunidade, levando os participantes a um momento e/ou uma característica limiar (TURNER, 1974).

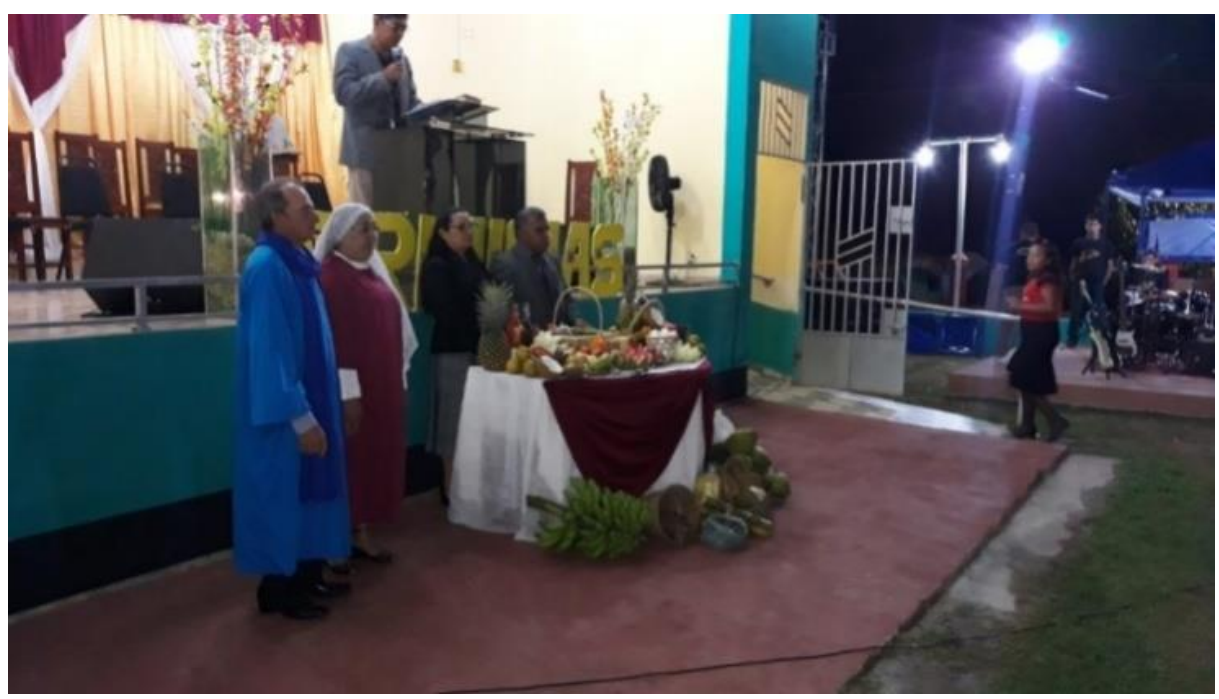

Figura 4: A solenidade de abertura. Fonte: Acervo das autoras, 2019

O sacerdote, que sempre é representado pelo pastor que preside a igreja, também participa da celebração com indumentárias que servem para dar maior veracidade à dramatização bíblica. Durante o ato, o sacerdote se posta atrás de uma mesa com os alimentos e na sequência, um diácono ou presbítero da igreja convida a todos os presentes para ficarem de pé para que a cerimônia aconteça com a leitura Livro de Deuteronômio capítulo 26, versículos de 3 a 10 (BATISTA, entrevista, 09/09/2019, Vila Verde 2019). À medida que a leitura acontece, as primícias são entregues ao sacerdote que ergue aos céus e depois coloca dobre a mesa. Ao término da leitura, o pastor faz uma oração em agradecimento a Deus pelas bênçãos e pelos frutos doados. Após esta primeira encenação, os personagens saem de seus postos e entra um outro grupo encenando uma coreografia e uma peça teatral (fig. 5). Aqui, os participantes se colocam em um atributo, um tempo e um espaço diferente de seu dia a dia. São assim despidos de 
suas atribuições mundanas e imbuídos da atmosfera ritual. Este momento limiar provoca o fortalecendo o sentimento de grupo, que é observado nas falas de união, fraternidade e comunhão da comunidade, quando questionadas sobre a festa das Primícias (TURNER, 1974).

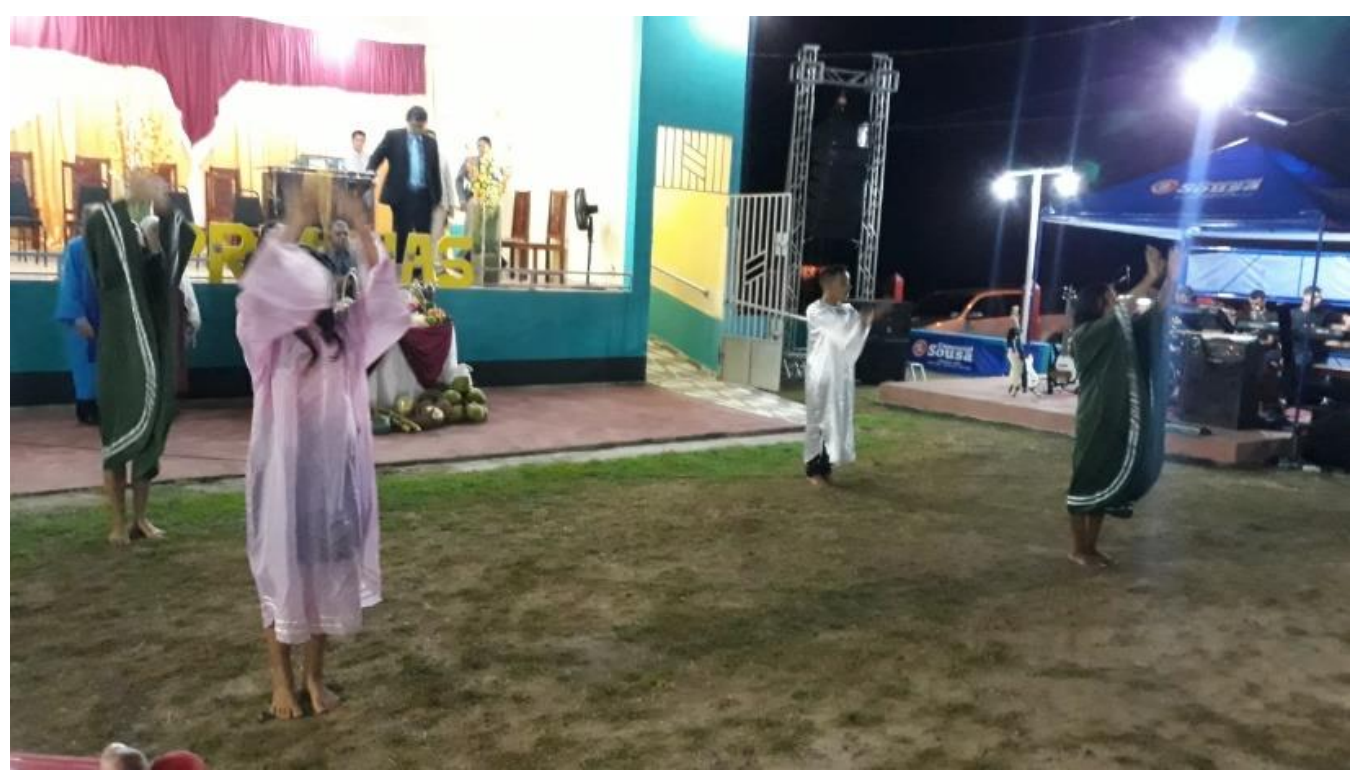

Figura 5: O teatro. Fonte: Acervo das autoras, 2019

A festa continua no sábado e a partir das $8 \mathrm{~h}$ acontece a cerimônia de consagração das primícias que foram doadas. O ritual inicia com oração e, em seguida, começam os louvores chamados de "avivamento espiritual" para que um pastor de outra cidade realize a sua pregação. Ao meio dia, encerra-se o momento de adoração e à tarde realizase a venda das primícias que ficam depositadas em um local denominado celeiro (fig. 3). Às $19 \mathrm{~h}$ acontece um grande culto de encerramento do evento, no qual há a presença de vários devotos de outros municípios. Muitos dizem que fizeram votos e receberam os seus pedidos, por isso estão agradecendo a Deus pela benção alcançada. Os testemunhos são de pessoas que não tinham onde plantar, mas conseguiram comprar um pedaço de terra após pedirem a Deus em festas anteriores. Hoje eles têm onde fazer seus plantios e criar seus animais. É relevante ressaltar que estas promessas não são feitas apenas pelos membros da Assembleia de Deus, mas também por fiéis de outras igrejas da região.

\section{Considerações finais}

O presente artigo teve como objetivo principal apresentar a festa das Primícias celebrada na comunidade de Vila Verde localizada no estado do Pará. Para tal, o texto 
permeou questões relacionadas à Assembleia de Deus, promotora da festa e neste estudo optou-se por descrever a festa da referida localidade, tendo como base um trabalho de campo, realizado no ano de 2019. Por meio da apresentação da festa das Primícias, foi possível perceber questões relativas às análises antropológicas das festas, principalmente pela ótica dos estudos sobre a religião e sobre o ritual. Não obstante a grande relevância de autores contemporâneos, a base teórica pautou-se em autores da dita Antropologia Clássica, como Durkheim (2003), Mauss (2003) e Turner (1974). Ademais, a fala de participantes, nos trouxe a percepção que este festejo assembleiano ultrapassa sua função religiosa e se mostra como um importante elemento cultural que mobiliza a comunidade de Vila Verde/PA.

\section{Notas:}

1. No último censo realizado no município de Augusto Correa em 2010, os habitantes declararam: 33.489 católicos apostólicos romanos, 15 católicos ortodoxos, 11 espíritas, 825 evangélicos sem determinação específica, 126 evangélicos missionários, 28 evangélicos adventista, 98 evangélicos batistas, 4.322 evangélicos pentecostais da Assembleia de Deus, 13 evangélicos pentecostais da Congregação do Brasil, 225 evangélicos pentecostais do Evangelho Quadrangular, 10 evangélicos pentecostais do Brasil para Cristo, 13 evangélicos pentecostais da Universal do Reino de Deus, 289 evangélicos pentecostais de outras igrejas, 218 testemunhas de Jeová, 10 de múltiplo pertencimento ou de religiosidade não determinada, 10 de religiosidade mal determinada e 930 pessoas declararam não ter religião (IBGE, 2020b). Apesar de não haver separação da religiosidade por distritos e vilas, na observação da pesquisa de campo realizada em 2019 em Vila Verde, a grande maioria frequenta a Assembleia de Deus.

2. A Festa de Shavuot, Pentecostes ou das Primícias é a segunda das três grandes festas judaicas. Ao longo dos tempos, a festa incluiu a realização da celebração da Aliança do Sinai, com o "dom" da Torá. No entanto, a sua característica agrícola nunca deixou de ser celebrada e é destacada pelo termo "primícias", que significa os primeiros frutos colhidos ou os primeiros animais nascidos de um rebanho. No contexto cristão, a festa incorporou comemoração do "dom" do Espírito Santo. Apesar de ter uma raiz única, a festa das Primícias ganhou particularidades singulares em cada região, sendo relevante destacar que este artigo trata da festa realizada na comunidade de Vila Verde/PA.

3. Os livros de base para a celebração são: Jeremias capítulo 5, versículos 25; Ėxodo capítulo 23, versículos 16; Êxodo capítulo 34 versículos 22 e Levíticos (BATISTA, entrevista, 09/09/2019, Vila Verde 2019).

4. É relevante destacar que o processo de Romanização ou Ultramontanismo proferido pela Igreja Católica no período de 1850 a 1870. A segunda metade do século XIX no Brasil foi marcada por profundas mudanças sociais e políticas e o trânsito das ideias de modernidade, 
modernização, laicidade e abolicionismo foram, aos poucos, cativando parte da sociedade brasileira. Nesse sentido, a Igreja Católica, antes estritamente vinculada ao Estado, passou a receber duras críticas dos grupos propagadores dos novos ideais e, como contraponto, promoveu no Brasil as ações reformistas com intuito do fortalecimento interno e da manutenção de seu poder. (LOTT, 2017). Na Amazônia, houve a efetiva preocupação não só de uma reforma interna da Igreja como também da evangelização da população (AZZI, 1983).

5. Há outras formas de apresentar a inserção do movimento pentecostal no Brasil. Brandão (1980 apud MARIANO, 1999) separa o movimento em dois grandes blocos: as Igrejas de Mediação, de cunho mais eruditos e as Pequenas Seitas, de cunho mais popular. Já Mariano (1999) segue a mesma divisão de Freston (1994), mas designa as ondas como: Pentecostalismo Clássico, Deuteropentecostalismo e Neopentecostalismo, respectivamente.

6. Não obstante Joel Robbins (2011) - um dos representantes da Antropologia do Cristianismo - trabalhar com a conversão dos Urapmin de Papua Nova Guiné e todas as complexidades que o tema apresenta, o ponto de sua teoria que entende a conversão religiosa como uma ruptura no antigo modo de viver é pertinente para este trabalho.

7. Isaias Rodrigues Ribeiro liderou a igreja durante seis anos e foi sucedido por Nadilson Gouveia, que também liderou por mais seis anos, saindo em janeiro de 2013. Na sequência assumiu Antônio Lisboa Batista que permanece até hoje como o pastor responsável.

8. Os alimentos doados para a Assembleia de Deus são vendidos para que haja um recolhimento de dinheiro que é revertido para a igreja e para a comunidade.

\section{Referências:}

ARAÚJO, Gilvan Leite de. A Festa de Shavnot - Pentecostes A Teo, Rio de Janeiro, v. 19, n. 50, p. 310-329, mai./ago, 2015. Disponível em https://www.maxwell.vrac.pucrio.br/25503/25503.PDF acesso dia 05 de fevereiro de 2020.

ADNB - ASSEMBLEIA DE DEUS NO BRASIL. História.Disponível em: http://adnb.com.br/historia-da-assembleia-de-deus/ Acesso dia 11 de junho de 2019.

AZZI, Riolando. A reforma Católica na Amazônia 1850\1870. In Religião e Sociedade $\mathrm{n}^{\circ} 10$. Rio de Janeiro, 1983, p. 21-30.

BATISTA, Antônio Lisboa. Assembleia de Deus. Entrevista concedida à autora em 09 de Setembro de 2019, Vila Verde/PA.

BOYER, Véronique. Trajetórias sociais e pertencimento religioso: três exemplos pentecostais. In: XX Reunião Brasileira de Antropologia. Salvador, abril de 1996.

CALLOIS, Roger O homem e o sagrado Lisboa: Edições 70, 1988. 
DURKHEIM, Émile As formas elementares da vida religiosa São Paulo: Martins Fontes, 2003.

FRESTON, Paul. Breve história do pentecostalismo brasileiro. In ANTONIAZZI et, al. Nem anjos nem demônios: interpretações sociológicas do pentecostalismo. Petrópolis: Vozes, 1994.

IBGE - Instituto Brasileira de Estatística e Geografia. Panorama. https://cidades.ibge.gov.br/brasil/pa/augusto-correa/panorama Acesso dia 12 de novembro de 2020a.

IBGE - Instituto Brasileira de Estatística e Geografia. Pesquisa religião.https://cidades.ibge.gov.br/brasil/pa/augusto-

correa/pesquisa/23/22107?detalhes=true Acesso dia 12 de novembro de 2020b.

LOTT, Wanessa PiresCenas festivas da/na cidade de Belo Horizonte:1897-1922. 2009 Dissertação (Mestrado) - Universidade Federal de Minas Gerais, Faculdade de Filosofia e Ciências Humanas, Belo Horizonte, 2009. Programa de Pós-Graduação em Antropologia.

LOTT, Wanessa Pires Tem festa de negro na República branca: o reinado em Belo Horizonte na Primeira República. 2017. Tese (Doutorado) - Universidade Federal de Minas Gerais, Faculdade de Filosofia e Ciências Humanas, Belo Horizonte, 2017. Programa de Pós-Graduação em História.

MACHADO, Mônica Sampaio. A territorialidade pentecostal: uma contribuição à dimensão territorial da religião. Revista Espaço e Cultura Rio de Janeiro, no 4, jun 1997. Disponível em https://www.epublicacoes.uerj.br/ojs/index.php/espacoecultura/article/view/6773 Acesso dia 02 de fevereiro de 2020.

MAFRA, Clara. Os pentecostais. Rio de Janeiro: Jorge Zahar, 2001.

MAPS, Google. Vila Verde. Disponível em https://www.google.com/maps/place/Vila+Verde/@-1.3249806,$46.2262004,17 \mathrm{z} /$ data $=! 3 \mathrm{~m} 1 ! 4 \mathrm{~b} 1 ! 4 \mathrm{~m} 5 ! 3 \mathrm{~m} 4 ! 1 \mathrm{~s} 0 \times 22 \mathrm{ae} 7 \mathrm{fe} 17 \mathrm{a} 58 \mathrm{~b} 365: 0 \times 60 \mathrm{~b} 07559 \mathrm{c} 60 \mathrm{dfc} 19$ ! 8m2!3d-1.3249806!4d-46.2240117 Acesso dia 26 de outubro de 2019.

MARIANO. Ricardo. Os pentecostais. São Paulo: Loyola, 1999.

MATOS, Alderi Souza de. O movimento pentecostal: reflexões a propósito do seu primeiro centenário Fides Reformata XI, $\mathrm{n}^{\circ}$ 2, 2006. Disponível em https://cpaj.mackenzie.br/wp-content/uploads/2018/11/2-O-movimento-pentecostal- 
reflex $\% \mathrm{C} 3 \% \mathrm{~B} 5$ es-a-prop $\% \mathrm{C} 3 \% \mathrm{~B} 3$ sito-do-seu-primeiro-centen $\% \mathrm{C} 3 \% \mathrm{~A} 1$ rio-AlderiSouza-de-Matos.pdf Acesso dia 11 de fevereiro 2020.

MATOS, Alderi Souza de. Breve história do protestantismo no Brasil Vox Faifae: Revista de Teologia da Faculdade FASSEBvol. 3, $\mathrm{n}^{\circ}$ 1, 2011. Disponível em http://www.faifa.edu.br/revista/index.php/voxfaifae/article/view/27 Acesso dia 11 de fevereiro 2020.

MAUSS, Marcel Sociologia e antropologia. São Paulo: Cosac \& Naify, 2003.

MAUSS, Marcel; HUBERT, Henri. Sobre o sacrifício São Paulo: Ubu editora, 2017.

MOURA, Luana Cristina Baracho de Igreja Pentecostal Assembleia de Deus: uma apreciação de sua espacialidade no Brasil Espaço e Cultura, n. 28, 2010. Disponível em https://www.e-publicacoes.uerj.br/index.php/espacoecultura/article/view/8084 Acesso dia 12 de fevereiro de 2020.

NOVAES, Regina. Os escolhidos de Deus Cadernos do ISER, nº 19, 1985.

PANTOJA, Vanda. Santos e Espirito Santo, ou católicos e evangélicos na Amarônia marajoara.2011. Tese (Doutorado) - Universidade Federal do Pará, Instituto de Filosofia e Ciências Humanas, Belém, 2011. Programa de Pós-Graduação em Ciências Sociais.

RIBEIRO, Isaias Rodrigues. Assembleia de Deus. Entrevista concedida à autora em 05 de agosto de 2019, Vila Verde/PA.

ROBBINS, Joel. Transcendência e antropologia do cristianismo: linguagem, mudança e individualismo Religião e Sociedade, Rio de Janeiro, 31(1): 11-31, 2011. Disponível em https://www.scielo.br/pdf/rs/v31n1/a02v31n1 Acesso dia 10 de novembro de 2020.

SILVEIRA. Assembleia de Deus. Entrevista concedida à autora em 15 de setembro de 2019, Vila Verde/PA. 1974.

TURNER, Victor. O Processo Ritual Estrutura e Anti Estrutura. São Paulo: Vozes, 